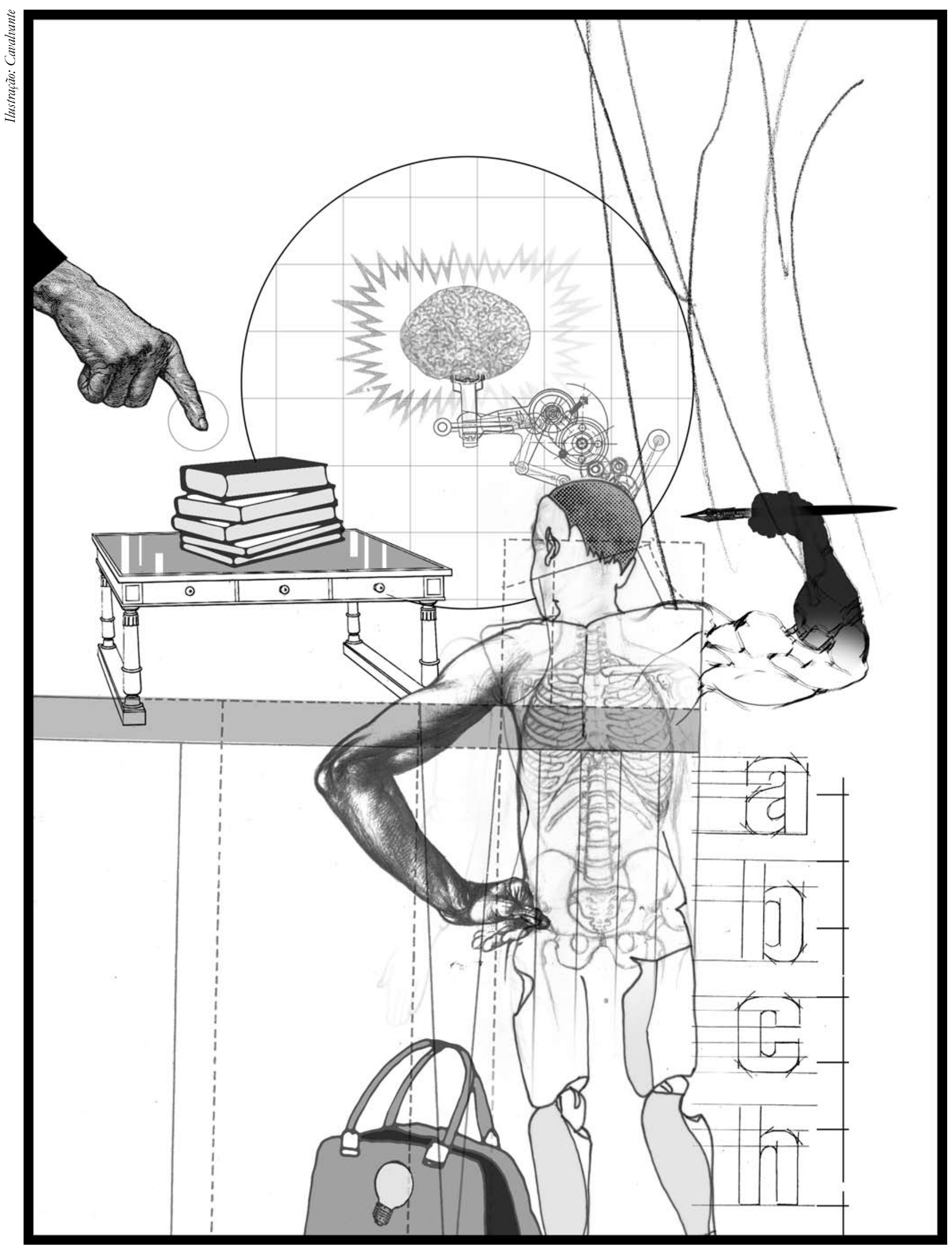




\title{
O Ensino Médio em Questão: A Análise de uma História Recente ${ }^{1}$
}

\author{
Ramon de Oliveira
}

\begin{abstract}
Resumo
Analisa-se a história recente do ensino médio brasileiro (1971-2006), tendo como referência as modificações ocorridas no sistema capitalista e suas implicações na prática pedagógica escolar e no financiamento da educação pública brasileira. Considera-se que nesse período, além da expressiva expansão das matrículas nas escolas das redes estaduais, foi pródigo o debate sobre a identidade social do ensino médio. Destaca-se que, em meio ao embate político entre a academia e setores ligados ao ensino tecnológico e o Governo Federal no referente à garantia da não dissociação entre a formação geral e profissional no ensino médio, mantém-se a indefinição da identidade social do ensino médio.
\end{abstract}

Palavras-chave: Ensino Médio; História da Educação; Política Educacional; Financiamento da Educação; Educação; Brasil.

\section{INTRODUÇÃO}

Tendo como referência o conjunto de modificações ocorridas no âmbito do capitalismo ao nível global e as novas exigências postas para a educação, enfatizaremos aqui a história recente da constituição da identidade do ensino médio brasileiro, priorizando o debate sobre a dualidade que sempre esteve presente na educação brasileira e a responsabilidade estatal para com o seu financiamento. Nesse sentido vale registrar, como afirmaram Harvey (1996), Arrighi (1996) e Hobsbawm (1995)², que a década de 1970 representa um ponto nodal para a análise das mudanças ocorridas no âmbito do capitalismo. Embora não possamos atribuir com precisão um momento específico da virada ou da transformação que ocorreu no interior do sistema capitalista, para estes autores, esse período demarca um momento no qual ele- ao passar por mais uma crise - encontrou na reestruturação produtiva a condição necessária à recomposição das suas declinantes taxas de acumulação.

Há análises segundo as quais o modelo caracterizado pelo trabalho fragmentado passou a ser superado por novas formas de produção e de organização empresarial. Essas análises (KUENZER, 1988; FIDALGO; MACHADO, 1994; MELLO, 1994; CEPAL, $1996^{3}$; entre outros) apontam que as modificações ocorridas no setor produtivo geram a necessidade de um novo perfil de trabalhador. Ou seja, não interessa mais ao processo

\footnotetext{
* Doutor em Educação pela Universidade Federal Fluminense, UFF. Mestre em Educação pela Universidade Federal de Pernambuco, UFPE. Professor do Departamento de Fundamentos Sócio-Filosóficos da Educação da UFPE. E-mail: ramono@elogica.com.br.
}

Recebido para publicação em: 07/12/07. produtivo um trabalhador que domine, exclusivamente, uma fração da produção. Estes autores destacam a importância do operário ser capaz não só de produzir com qualidade e destreza, mas, principalmente, de adaptar-se às novas situações de produção.

Decorrente desse conjunto de modificações e exigências impostas pelo movimento de reestruturação do capital, o Brasil, seguindo a tendência mundial, passou a destacar maior atenção, pelo menos ao nível do discurso, à educação.

É nesse contexto que são percebidas modificações no ensino médio brasileiro. Modificações que dizem respeito à sua ampliação, à sua estrutura pedagógica, ao seu financiamento e a sua relação com as modificações ocorridas no mundo do trabalho.

Passadas mais de duas décadas desde que, pela primeira vez, tentou-se estabelecer uma reestruturação na identidade do ensino médio no Brasil, através da Lei 5.692/714, ainda nos voltamos para o debate sobre qual a verdadeira função social da última etapa da educação básica. Desde essa lei, estabeleceram-se debates ou existiram ações impositivas por parte do Governo Federal procurando dar um fim a essa não-resolução. A falta de um consenso a esse respeito é a expressão da própria contradição social que existe na sociedade brasileira, impedindo a resolução, no âmbito legal, de uma questão que se estrutura a partir da dualidade social característica da sociedade capitalista e cada vez mais evidente na realidade brasileira.

Podemos constatar que a Lei de Diretrizes e Bases da Educação Nacional (Lei 9.396/945 ) estabeleceu que o ensino médio não teria como objetivo formar trabalhadores para os interesses imediatos do mercado de trabalho. O Decreto 2.208/976 determinou a separação da educação profissional da formação geral e reafirmou a cisão entre a formação para o trabalho e a formação para a continuidade dos estudos. Com o início da gestão do 
presidente Luís Inácio Lula da Silva, reacendeu o debate sobre a identidade do ensino médio, levando a que, no ano de 2004, o governo brasileiro, através do Decreto $5.154 / 2004^{7}$, tornasse sem valor o decreto anteriormente citado e reafirmasse a possibilidade da articulação entre a formação para o trabalho e a preparação para a continuidade dos estudos na última etapa da educação básica.

Mesmo o atual governo tendo se mostrado aberto a dialogar com a sociedade no referente aos rumos da educação profissional e do ensino médio ${ }^{8}$, permanece latente a necessidade de avançarmos na constituição de um projeto de educação básica, particularmente para o ensino médio que de fato seja coerente e coetâneo às mudanças ocorridas nos âmbitos social, político e econômico e que esteja atento aos interesses da classe trabalhadora.

Nesse sentido, este trabalho objetiva analisar o movimento de constituição da identidade do ensino médio brasileiro, tendo como referência o debate promovido por pesquisadores cuja produção identifica-se com tal questão, considerando as modificações no âmbito da legislação e outros fatores pertinentes à melhor compreensão dos determinantes e constituintes da última etapa da educação básica brasileira.

\section{A educação brasileira no CONTEXTO DAS MUDANÇAS SOCIETÁRIAS}

Observamos uma modificação substancial dos valores que passam a ser norteadores da educação brasileira. Se, nos anos 1980, início do processo de redemocratização, estavam presentes nos planos educacionais de municípios e estados a valorização da formação de sujeitos mais críticos, voltados para uma intervenção política no interior da sociedade, atualmente percebe-se que tais objetivos perdem espaço para um projeto educacional que tem como horizonte a formação de sujeitos mais capazes de competir por uma vaga no mercado de trabalho, considerados peças fundamentais no processo de desenvolvimento econômico da nação.

O discurso classista direcionado à confecção de sujeitos autônomos e críticos ao modelo capitalista de produção é tomado de assalto por proposições educacionais que elegem como fundamental a formação de indivíduos voltados para a competição, para a disputa, para o individualismo. Embora essas características não sejam defendidas oficialmente, ocupam, de modo sorrateiro, o espaço educacional, na medida que, cada vez mais, defende-se que o alcance da cidadania tem como requisito básico a capacidade dos indivíduos adquirirem, no mercado, os bens necessários à sua sobrevivência. Pela ênfase na ideologia meritocrática, afirma-se que só os mais habilitados serão capazes de conquistar esses bens.

A valorização do pragmatismo, o reducionismo da problemática educacional a questões de ordem técnicas e gerenciais reforçam, no âmbito escolar, a descontextualização e a leitura enviesada dos reais fatores determinantes dos resultados negativos que ainda temos no sistema educacional brasileiro.

A busca de soluções imediatas para as dificuldades de aprendizagem faz com que se elejam como culpados dos problemas educacionais fatores que são, eles próprios, decorrentes das prioridades governamentais na política educacional. A má formação docente, a qualidade dos livros didáticos, o gerencia- - mento da educação, são tomados como maiores responsáveis pela má qualidade da educação. No entanto, oculta-se que aqueles à frente do Poder Executivo, como forma de atender aos interesses das agências financeiras internacionais, paulatinamente, destinaram menores recursos para educação.

Por outro lado, a dificuldade de participação da sociedade na formulação e implementação das políticas educacionais permitiu que o governo brasileiro, ao nível central, juntamente com seus seguidores municipais e estaduais, adequassem a política educacional ao receituário de agentes externos à realidade brasileira. Estes, particularmente o Banco Mundial e o Banco Interamericano de Desenvolvimento- defensores do credo da teoria do capital humano-, não visualizam na prática educativa um momento fundamental para a confecção de novas consciências solidárias. O fundamental para essas instituições é que a educação esteja voltada para a formação de uma mão-de-obra capacitada para adequarse aos novos requisitos impostos pela reestruturação produtiva (OLIVEIRA, 2006). ${ }^{9}$ Nesse sentido, o reducionismo educacional se torna muito mais forte, uma vez que a educação passa a ser gerida de forma semelhante ao ocorrido no processo fabril.

Nessa aproximação e submissão do papel da escola ao que interessa ao setor produtivo, "reestruturações" pedagógicas desencadeiam-se no âmbito escolar de forma a garantir que o sistema educacional apresente produtividade nas taxas de aprovação, bem como diminuam os índices de evasão.

Movimentos desencadeados na arena educacional, como o paradigma da qualidade total na educação- o qual buscava uma maior excelência no processo de ensino escolar (RAMOS, 1992) ${ }^{10}$, bem como seu sucessor, a pedagogia das competências, devidamente criticados por pesquisadores brasileiros (GENTILI; SILVA, 1996 e 1994; GENTILI, 1995 e 1998; FIDALGO; 
MACHADO, 1994; RAMOS, 2001 ${ }^{11}$, entre outros) tentaram estabelecer na cotidianidade da escola uma aproximação entre a formação ali desencadeada e o que interessa ao capital no seu processo de reestruturação.

O ensino médio, talvez, seja aquele que mais sofreu essa ofensiva do capital, uma vez que - tem um papel funcional ao requisitado pelo mercado de trabalho, e também por representar a etapa de consolidação da formação profissional para uma parte da juventude que almeja inserir-se no mercado de trabalho.

\section{ENSINO MÉDIO: A NÃO SUPERAÇÃO DA DUALIDADE NO ÂMBITO DA LEI}

Em 1971, com a Lei 5.692/71 ${ }^{12}$, o governo brasileiro havia estabelecido a obrigatoriedade da articulação da formação profissional e geral no âmbito do então $2^{\circ}$ grau. Contudo, a mesma mostrou-se incapaz de colocar-se por sobre a dualidade que estrutura historicamente a educação brasileira (KUENZER, 2002, SAVIANI, 1987). ${ }^{13}$

Se havia, por parte do legislador, o interesse em acabar com a histórica dicotomia entre a formação profissional e a formação geral, tal dispositivo legal asseverou as diferenças de qualidade entre a escola pública e a privada, uma vez que existiram diversos mecanismos por parte das escolas particulares de burlarem a legislação e manterem-se voltadas, primordialmente, para a garantia da continuidade dos estudos dos seus alunos no ensino superior. E, por outro lado, foram inúmeros e muitas vezes insuperáveis os obstáculos com os quais se depararam as escolas públicas para adequar seus currículos, sua infra-estrutura, bem como garantir um corpo docente qualificado técnica e pedagogicamente à nova realidade imposta para o ensino de $2^{\circ}$ grau (LEITE; SAVI, 1980) ${ }^{14}$.

Sobre a 5.692/71 e sua intenção de acabar com a dicotomia entre a formação geral e a formação profissional, vale a pena referir-se ao texto de Franco e Durigan (1984) ${ }^{15}$, o qual, embora fizesse algumas críticas à dita lei, destacou que ela representou uma ruptura brusca com o modelo até então vigente, pois, para elas, as reformas anteriores foram conciliatórias e reformistas, mantiveram-se dentro da ordem. Segundo as autoras, a referida lei visou quebrar a dualidade histórica no sistema educacional brasileiro; entretanto, a mesma logrou mau resultado em virtude, entre outros fatores, de não ter levado em consideração a cultura da sociedade brasileira e não ter se mostrado sensível ao que era desejado por pais, alunos e professores, terminando por levar a falsificação grosseira das suas finalidades.

$\mathrm{Na}$ mesma linha de argumentação desenvolvida por essa autoras, Gomes $(1982)^{16}$, também referindo-se à cultura brasileira em relação papel do ensino de $2^{\circ}$ grau, ressaltou a cultura discriminatória na qual se valoriza a formação acadêmica em detrimento da formação profissional. Dessa forma, evidencia-se mais ainda, a partir da análise desses autores, que a identidade do ensino médio não é algo a ser definido apenas no âmbito legal, mas fundamentalmente na esteira de um projeto educativo que seja a síntese de interesses classistas e divergentes existentes no interior da sociedade brasileira.

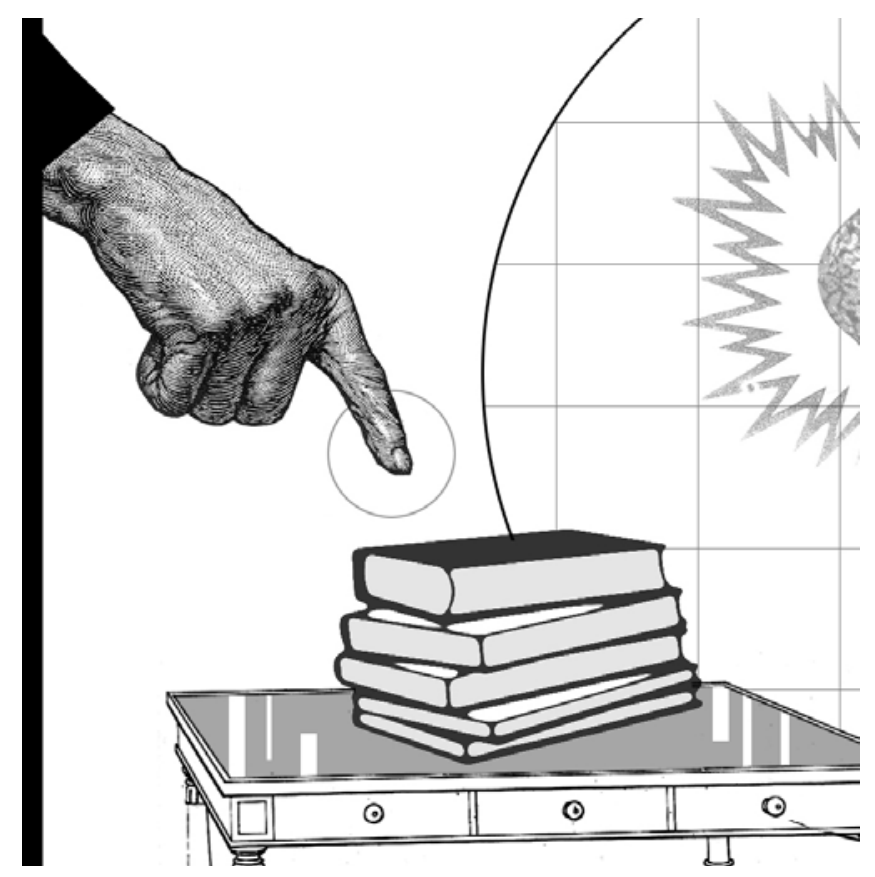

É importante destacar que o advento da 5.692/71 ${ }^{17}$, assim como as medidas legais desencadeadas nesta última década, articulam-se diretamente como momento político e econômico atravessado pelo capital ao nível global e, mais especificamente, pelo movimento de adaptação da economia nacional à divisão internacional do trabalho.

Naquele momento, 1971, houve um movimento de subordinação dos aparelhos de Estado ao movimento de soerguimento da economia nacional. O sistema educacional, como outras instâncias societárias, sofreu diretamente a influência do poder instituído, visando tornar-se uma alavanca do processo de desenvolvimento econômico. Ao mesmo tempo, à educação atribuiu-se um duplo papel a serviço do novo projeto social e político imposto à sociedade brasileira: viabilizar o aumento da produtividade econômica e incrementar o processo de distribuição de renda, haja vista os trabalhadores passarem a dispor também de um capital a ser investido/trocado no mercado, possibilitando-lhes um aumento dos seus rendimentos e, conseqüentemente, uma ascensão social (RODRIGUES, 1981) ${ }^{18}$.

Os anos da década de 1990, bem como os iniciais da atual década, dão continuidade ao objetivo de colocar a economia brasileira em um novo patamar de disputa na competição internacional. Após termos vivido, na década de 1980, uma situação preocupante no referente aos índices de crescimento econômico-sendo esse período considerado pela Cepal a década perdida (CEPAL, 1992) ${ }^{19}$ - , nos anos 1990, sob a batuta do então presidente Fernando Collor, instituíram-se ações objetivando tornar a economia brasileira mais competitiva. Foram desenvolvidos projetos, como o Programa Brasileiro de Qualidade e Produtividade (1990), que demonstram o quanto o Governo Federal estava interessado em garantir uma nova dinâmica à economia brasileira.

O empresariado industrial também demonstrou o quanto visava estabelecer novos rumos à economia nacional. Tendo à 


\section{as classes dominantes}

\section{brasileiras não tinham}

como objetivo assegurar

como obrigação do Estado

o financiamento do ensino

médio e nem tinham o

propósito de garantir à

classe trabalhadora uma

escolarização além do ensino

fundamental.

frente à Confederação Nacional das Indústrias (CNI) e a Federação das Indústrias do Estado de São Paulo (Fiesp), desencadeou ações com o objetivo de pressionar Governo Federal a estabelecer uma nova dinâmica econômica e, para tanto, exigiu uma nova agenda estatal, na qual a preocupação com a educação ocupasse posição destacada (OLIVEIRA, 2005) ${ }^{20}$.

Semelhante ao que ocorrera nos anos 1970, a educação passou a ser considerada um instrumento fundamental no processo de fortalecimento econômico (CEPAL, 1992) $)^{21}$. Destaca-se o fato de que, daquela vez, vários setores passam a explicitar não só o quanto o investimento na educação poderia trazer benefícios econômicos, como, ao mesmo tempo, seria um instrumento imprescindível no combate à crise do emprego e na diminuição das altas taxas de pobreza (OLIVEIRA, 2006) ${ }^{22}$. A partir de então podemos detectar um movimento de maior atenção ao ensino médio.

Nesse movimento de maior atenção ao ensino médio, podemos destacar que, após um longo período sem maiores novidades em relação às questões referentes à sua identidade- uma vez que a obrigatoriedade da formação profissional ao nível do então $2^{\circ}$ grau foi extinta com a Lei Federal n. ${ }^{0} 7.044 / 82^{23}$-, o que talvez tenha alcançado maior destaque foi o fato das forças progressistas terem conseguido que, no texto da carta magna brasileira, em seu artigo 208, inciso II, fosse assegurada "progressiva extensão da obrigatoriedade e gratuidade ao ensino médio".

Entretanto, como procuramos mostrar ao longo deste trabalho, a questão do ensino médio deve ser vista, antes de tudo, numa arena de disputa e no âmbito da relação de forças entre classes politicamente antagônicas, as quais, na medida do possível, procuram materializar no âmbito legislativo o seu projeto educacional e societal. É nesse sentido que deve ser registrado o retrocesso ocorrido com a Emenda Constitucional $14^{24}$, aprovada em 12 de setembro de 1996, alterando o artigo anteriormente citado, dando ao mesmo a seguinte redação: "Progressiva universalização do ensino médio gratuito".

Tal fato evidencia que as classes dominantes brasileiras não tinham como objetivo assegurar como obrigação do Estado o financiamento do ensino médio e nem tinham o propósito de garantir à classe trabalhadora uma escolarização além do ensino fundamental. Em outras palavras, mesmo em meio a um movimento que ganhava proporções cada vez maiores de que era necessário um maior investimento e comprometimento do poder público com a educação básica, principalmente daqueles setores que visualizam a educação na perspectiva economicista (OLIVEIRA, 2005 e 2006) ${ }^{25}$, o poder público brasileiro virava as costas para essa realidade e procurava manter-se distante da responsabilidade de ampliar o financiamento da educação e garantir uma escola de ensino médio de qualidade para os estudantes oriundos da classe trabalhadora.

Com a Lei de Diretrizes e Bases da Educação Nacional (LDB - Lei n. ${ }^{\circ}$ 9.394/19966 $6^{26}$, assegurou-se o ensino médio como última etapa da educação básica. Se, por um lado, tal fato expressa uma evolução no referente à possibilidade de mais anos de escolarização em virtude da ampliação da educação básica, registra-se o fato de que o mesmo foi colocado sob responsabilidade prioritária dos estados, não tendo sido incorporado, no âmbito da legislação, um comprometimento maior do Governo Federal com seu financiamento.

Outro ponto a ser destacado em relação à presença do ensino médio no âmbito da LDB diz respeito a um descompromisso real dessa etapa da educação básica em relação à preparação direta e específica para uma profissionalização. Se, por um lado, tal ação reflete uma possível determinação de uma identidade definitiva para o ensino médio, por outro expressou uma tentativa do poder público de descomprometer-se com os gastos da educação profissional.

Não menos importante a se destacar na relação entre $O$ ensino médio e a educação profissional, no texto final da LDB, quanto o mesmo não incorporou a contribuição da sociedade organizada no referente a esta última etapa da educação básica pautar-se por princípios da politecnia.

Naquele momento, ainda que no âmbito das relações de classes não tivessem sido superados os obstáculos a uma educação de caráter politécnico, havia, pelo menos, a compreensão de avançar-se na perspectiva de um projeto de escola de ensino médio superador da visão dicotômica entre a formação geral e formação profissional. Contudo, o texto aprovado, desrespeitando os debates e a produção existente, bem com o projeto aprovado na Comissão de Educação, Cultura e Desporto, não só excluiu a perspectiva de educação politécnica, como também descartou o período de quatro anos, como tempo de realização do ensino médio (FRIGOTTO et al., 2005) ${ }^{27}$.

O texto da LDB aprovado representou uma imposição e uma manobra governamental para aprovar o modelo de educação que mais interessava às elites. Para aqueles que há muito discutiam e defendiam um projeto de educação básica de caráter politécnico 
sob os moldes propostos por Antonio Gramsci $(1985)^{28}$, representou, no plano legal, a impossibilidade de, naquele momento, avançar-se para uma escola identificada com a formação integral dos educandos.

Concomitantemente ao movimento de elaboração e aprovação da $\mathrm{LDB}$, estava estruturando-se a reforma da educação profissional e do ensino médio brasileiros.

Inicializada no âmbito legal com o encaminhamento ao Congresso Nacional do Projeto de Lei $1.603 / 96^{29}$ e concretizada com o Decreto $2.208 / 97^{30}$, essa reforma explicitava a posição das elites nacionais de tornarem legal a dicotomia entre a formação profissional e a formação geral, e a tentativa de sacramentarem, mais uma vez, no plano legal, a impossibilidade de constituir no âmbito do ensino médio e em toda a educação básica, um projeto de escola sob os moldes da politecnia.

Naquele momento, havia no interior do governo brasileiro uma discussão sobre os encaminhamentos a serem efetivados de forma a estruturar-se um novo ensino médio e uma nova educação profissional. Tal discussão tinha como protagonistas o Ministério do Trabalho e o Ministério da Educação. Entretanto, segundo Kuenzer $(1997)^{31}$, houve um certo atropelo das discussões por parte do Ministério da Educação objetivando dar respostas satisfatórias ao Banco Mundial. Ou seja, a reforma que se estabeleceu no âmbito do ensino médio brasileiro e que afetou mais diretamente as instituições de ensino médio que ministravam a educação profissional não pôde ser avaliada sem considerar-se a cumplicidade das elites nacionais com o projeto de educação estruturado pelo Banco Mundial (OLIVEIRA, 2006; BUENO, 2000; CUNHA, 2003) $)^{32}$.

Com a desvinculação da educação profissional do ensino médio, através do Decreto 2.208/9733, o MEC impôs - pela reforma - um retrocesso no campo educacional. A reforma estabeleceu a quebra na equivalência nestas modalidades de ensino, alcançada com a LDB de 1961.

O governo brasileiro, em 2004, através do Decreto $5.154 / 2004^{34}$, tornou sem valor o decreto anteriormente citado e reafirmou a possibilidade da articulação entre a formação para o trabalho e a preparação para a continuidade dos estudos na última etapa da educação básica.

Esse último decreto representou a sensibilidade governamental às vozes e escritos das mais distintas partes da nação brasileira, que eclodiram no sentido de reafirmar o papel do ensino médio enquanto momento social e pedagogicamente necessário para que os estudantes das camadas populares pudessem ter acesso a uma preparação para uma futura inserção no mercado de trabalho. Entretanto, como destacou Frigotto et al. $(2005)^{35}$, o ensino médio integrado "conquanto seja uma condição social e historicamente necessária para a construção do ensino médio unitário e politécnico, não se confunde com ele...". Ou seja, embora reconheça-se o quanto tenha sido uma conquista a revogação do Decreto 2208/97 e tenhamos avançado na perspectiva de articular a formação geral e formação profissional, tais fatos ainda não se configuram como expressão de um asseguramento da educação politécnica. Afinal, como destacaram outros autores (KUENZER, 2002; SAVIANI, $1987)^{36}$, a educação que de fato interessa à classe trabalhadora só poderá efetivamente edificar-se em uma sociedade que esteja pautada em relações que neguem os princípios constituintes da lógica capitalista.

Para Saviani $(1987)^{37}$, a dualidade entre educação profissional e educação geral deve ser compreendida a partir das relações capitalistas de produção e explicita que a fragmentação existente no processo educacional é a própria expressão da apropriação desigual da produção material existente. Da mesma forma que se observa uma divisão entre proprietários e não proprietários dos meios de produção, estabelece-se também no processo de ensino uma dualidade entre o ensino para aqueles que devem comandar (ensino científico-intelectual) e o ensino profissional para os que devem ser comandados.

O caráter dual que predomina na história do ensino médio brasileiro decorre do projeto excludente que as classes economicamente dominantes conseguiram tornar vitorioso. Mesmo quando observamos um crescimento do número de matrículas nesse nível de ensino, não é desconhecido o quanto esse fato está articulado à diminuição da qualidade do ensino, provocando que os jovens brasileiros apresentem um nível de aprendizagem bem abaixo do aceitável.

Contraditoriamente, mas na mesma lógica do processo de exclusão da classe que vive do trabalho, a história do ensino médio é a história da inclusão daqueles que puderam e podem, em virtude de uma condição de classe distinta, apropriar-se da produção material e não material existente (KUENZER, 2002) ${ }^{38}$.

\section{CoNSIDERAÇõES FINAIS}

Atualmente contamos com mais de nove milhões de alunos matriculados no ensino médio, o que representa, nos últimos 15 anos, um crescimento superior a 135\%. As redes estaduais podem ser consideradas as principais responsáveis por esse crescimento, uma vez que cresceram nesse mesmo período mais de $205 \%$ e abrigam um contingente próximo a $85 \%$ do total das matrículas.

O aumento sistemático de vagas nas escolas estaduais tem contribuído para a diminuição de matrículas no curso noturno. Além disso, é possível constatar uma maior presença estudantes

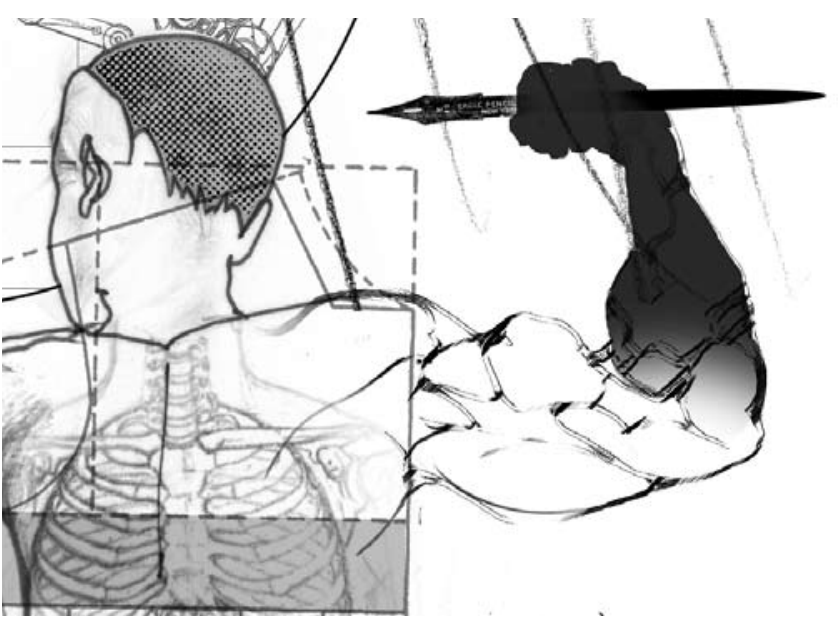


na faixa etária de 15 a 17 anos, o que expressa uma diminuição da distorção série/idade.

Mesmo com a ampliação de matrículas, constatamos um descompromisso estatal com o financiamento do ensino médio. Observa-se uma realidade marcada por escolas sucateadas, professores mal pagos e em número insuficiente, ausência de bibliotecas, déficit no número de carteiras, problemas com iluminação, falta de água potável, infra-estrutura precária etc.. Problemas que enfrentam as escolas públicas brasileiras e que levam os alunos a chegarem ao final da educação básica em condições extremamente deficitárias, seja para disputar um emprego ou para continuar seus estudos.

Os dados oriundos do Exame Nacional do Ensino Médio evidenciam o quanto esse crescimento tem sido acompanhado da persistente diferença na aprendizagem dos estudantes das escolas estaduais e privadas. Diferença essa que não se apresenta quando comparamos estudantes oriundos das instituições federais com os da rede privada, evidenciando que a desigual aprendizagem decorre, entre outros fatores, da falta de financiamento e de valorização dos profissionais do magistério das redes estaduais.

Por todo exposto, concluímos este trabalho destacando o fato de que há necessidade de avançarmos na definição da identidade do ensino médio e, fundamentalmente, modificarmos a sua política de financiamento.

Nos deparamos com uma situação na qual não pode persistir a visualização do ensino médio voltado para a formação profissional ou destinado à continuidade dos estudos.

A integração entre a formação profissional e a formação geral afirma-se como necessária à educação de um novo ser social. Ser que seja capaz de articular o conhecimento produzido no campo da ciência, na sua dimensão mais ampla, e ter conhecimento dos movimentos estruturadores da produção capitalista mais moderna, de forma a poder intervir nas várias áreas abertas à intervenção humana.

Cabe à escola e, particularmente ao ensino médio, garantir uma formação que esteja além daquela necessária à formação profissional específica, superando o academicismo livresco e indiferente ao ocorrido no mundo do trabalho e às necessidades econômicas dos estudantes oriundos da classe trabalhadora.

A luta e a disputa pela instauração de uma educação de caráter politécnico mantêm-se como politicamente importantes e pedagogicamente necessárias, na medida que se vislumbra a formação de pessoas para além das necessidades imediatas impostas pelo movimento do capital.

No âmbito do seu financiamento, a realidade tem demonstrado que é extremamente necessário o Governo Federal articular-se com os governos estaduais para ampliar os recursos destinados à melhoria da infra-estrutura das escolas e aos salários dos professores. A aprovação do Fundeb (Fundo de Manutenção e Desenvolvimento da Educação Básica e de Valorização dos Profissionais da Educação) é um passo nesse sentido, mas ainda representa uma medida muito tímida, uma vez que os recursos que o Governo Federal disponibiliza para a sua complementação serão disputados por todas as modalidades componentes da educação básica.
Nesse sentido, entendemos ser necessário que o ensino médio seja tratado como de responsabilidade dos estados e da União o que expressa uma concepção de responsabilização financeira da União bem diferente do definido para o Fundeb.

\section{Notas:}

1 Este trabalho é uma versão reformulada do texto apresentado no VIII Congreso Iberoamericano de Historia de la Educación Latinoamericana: Contactos, cruces y luchas en la bistoria de la educación latinoamericana, realizado na cidade de Buenos Aires, Argentina, entre os dias 30 de outubro e 2 de novembro de 2007.

2 HARVEY, David. Condição pós-moderna. 6a ed. São Paulo : Loyola, 1996; ARRIGHI, Giovanni. O longo século XX: dinheiro, poder e as origens do nosso tempo. Rio de Janeiro : Contraponto, 1996; HOBSBAWM, Eric J. A era dos extremos: o breve século XX: 1914-1991. São Paulo : Companhia das Letras, 1995.

3 KUENZER, Acácia Zeneida. Ensino de $2^{\mathbf{O}}$ grau: o trabalho como princípio educativo. São Paulo : Cortez, 1988; FIDALGO, Fernando Selmar; MACHADO, Lucília Regina de Souza. Controle da qualidade total: uma nova pedagogia do capital. Belo Horizonte : Movimento de Cultura Marxista, 1994; MELLO, Guiomar Namo de. Cidadania e competitividade: desafios educacionais do terceiro milênio. $3^{\text {a }}$ ed. São Paulo : Cortez, 1994; CEPAL. Transformación productiva con equidad: la tarea prioritaria del desarrollo de América Latina y el Caribe en los años noventa. Santiago de Chile, 1996.

4 BRASIL. Leis, Decretos. Lei n. ${ }^{\circ}$ 5.692, de 11 de agosto de 1971. Diário Oficial [da] República Federativa do Brasil, Brasília, 12, ago., 1971. Seção 1. p. 6.377. Fixa as Diretrizes e Bases para o ensino de primeiro e segundo graus, e dá outras providências.

5 Id. Lei n. ${ }^{\circ}$ 9.394, de 20 de dezembro de 1996. Diário Oficial [da] República Federativa do Brasil, Brasília, 23 dez. 1996. Estabelece as Diretrizes e Bases da Educação Nacional.

6 Id. Decreto n. ${ }^{\circ}$ 2.208, de 17 de abril de 1997. Diário Oficial [da] República Federativa do Brasil, Brasília, 18 abr. 1997. Regulamenta o \ $2^{\circ}$ do art. 36 e os arts. 39 a 42 da Lei n. ${ }^{\circ} 9.394$, de 20 de dezembro de 1996, que estabelece as Diretrizes e Bases da Educação Nacional.

Id. Decreto n. ${ }^{\circ}$ 5.154, de 23, julho de 2004. Diário Oficial [da] República Federativa do Brasil, Brasília, 26, jul., 2004. p. 18, seção 1. Regulamenta o parágrafo $2^{\circ}$ do art. 36 e os arts. 39 a 41 da Lei 9.394, de 20 de dezembro de 1996, que estabelece as Diretrizes e Bases da Educação Nacional, e dá outras providências.

8 Em 2003, primeiro ano do governo Lula, foram realizados dois grandes encontros nacionais com a presença de pesquisadores, professores, gestores etc., com o objetivo de discutir o ensino médio e a educação profissional.

9 OLIVEIRA, Ramon de. Agências multilaterais e a educação profissional brasileira. Campinas : Alínea, 2006.

10 RAMOS, Cosete. Excelência na educação: a escola de qualidade total. Rio de Janeiro : Qualitymark, 1992.

${ }^{11}$ GENTILI, Pablo; SILVA, Tomaz Tadeu da. (Org.). Escola S.A: quem ganha e quem perde no mercado educacional do neoliberalismo. Brasília : CNTE, 1996; GENTILI, Pablo; SILVA, Tomaz Tadeu da. (Org.) Neoliberalismo, qualidade total e educação: visões críticas. Petrópolis : Vozes, 1994; GENTILI, Pablo (Org.). Pedagogia da exclusão: crítica ao neoliberalismo em educação. Petrópolis : Vozes, 1995; GENTILI, Pablo. A falsificação do consenso: simulacro e imposição na reforma educacional do neoliberalismo. Petrópolis : Vozes,1998; FIDALGO, Fernando Selmar ; MACHADO, Lucília Regina de Souza (1994). op. cit.; RAMOS, Marise N. A pedagogia das competências: autonomia ou adaptação. São Paulo : Cortez, 2001. 
12 BRASIL. Leis, Decretos. Lei n. ${ }^{\circ}$ 5. 692, de 11de agosto de 1971. op. cit.

${ }^{13}$ KUENZER, Acácia Zeneida (Org.). Ensino médio: construindo uma proposta para os que vivem do trabalho. $3^{a}$ ed. São Paulo : Cortez, 2002; SAVIANI, Dermeval Sobre a concepção de politecnia. Rio de Janeiro : Fiocruz. Politécnico de Saúde Joaquim Venâncio, 1987.

${ }^{14}$ LEITE, Marina Ribeiro; SAVI, Rita de Cássia Barros. Ensino de $2^{\circ}$ grau profissionalizante. Cadernos de Pesquisa, São Paulo, n. 36, p. 3-25, fev., 1980.

${ }^{15}$ FRANCO, Maria Laura ; DURIGAN, Maria Inês S. O aluno de cursos profissionalizantes a nível de $2^{\circ}$ grau: um retrato sem retoques. Cadernos de Pesquisa, São Paulo, n. 48, p. 47-56, fev. 1984.

${ }^{16}$ GOMES, Cândido Alberto da Costa. Modelos de mobilidade social no Brasil: educação acadêmica e profissionalizante em perspectiva histórica. Cadernos de Pesquisa, São Paulo, n. 40, p. 23-33, fev., 1982.

${ }^{17}$ BRASIL. Leis, Decretos. Lei n. ${ }^{\circ}$ 5. 692, de 11 de agosto de 1971. op. cit.

${ }^{18}$ RODRIGUES, Neidson. Estado e educação no Brasil. Educação e Sociedade, Campinas, n. 10, p. 41-53., 1981.

${ }^{19}$ CEPAL. Educación y conocimiento: eje de la transformación productiva con equidad. Santiago de Chile, 1992.

${ }^{20}$ OLIVEIRA, Ramon de. Empresariado industrial e educação brasileira: qualificar para competir. São Paulo : Cortez, 2005.

${ }^{21}$ CEPAL (1992). op. cit.

22 OLIVEIRA, Ramon de. Agências multilaterais e a educação profissional brasileira. Campinas : Alínea, 2006.

${ }^{23}$ BRASIL. Leis, Decretos. Lei n. ${ }^{\circ}$ 7.044, de 18 de outubro de 1982. Diário Oficial [da] República Federativa do Brasil, Brasília, 19, out. 1982. p. 19.539, seção 1. Altera dispositivos da Lei n. ${ }^{\circ}$ 5.692, de 11 de agosto de 1971, referentes a profissionalização do ensino de $2^{\circ}$ grau.

${ }^{24}$ BRASIL. Congresso. Emenda Constitucional n. ${ }^{\text {O } 14}$, de setembro de 1996. Diário Oficial [da] República Federativa do Brasil. Brasília, 13, set., 1996. p. 18.109, seção 2. Modifica os artigos 34, 208, 211 e 212 da Constituição Federal e da nova redação ao artigo 60 do ato das disposições constitucionais transitórias.

${ }^{25}$ OLIVEIRA, Ramon de $(2005 ; 2006)$. op. cit.

${ }^{26}$ BRASIL. Leis, Decretos. Lei n. ${ }^{\circ}$ 9.394, de 20 de dezembro de 1996. op. cit.

${ }^{27}$ FRIGOTTO, Gaudêncio et al. (Orgs.) Ensino médio integrado: concepções e contradições. São Paulo : Cortez, 2005.

${ }^{28}$ GRAMSCI, Antonio. Os intelectuais e a organização da cultura. Rio de Janeiro : Civilização Brasileira, 1985.

29 BRASIL. Leis, Decretos. Medida Provisória n. ${ }^{\circ} 1.603$, de 27, novembro de 1997. Diário Oficial [da] República Federativa do Brasil, Brasília, 28 nov. 1997. p. 27.937, seção 1. Acresce parágrafos ao artigo 18 da Lei 9.293, de 15 de julho de 1996, que dispõe sobre as diretrizes para a elaboração da lei orçamentária para o exercício de 1997.

${ }^{30}$ BRASIL. Leis, Decretos. Decreto n. ${ }^{\circ} 2.208$, de 17 de abril de 1997. op. cit.

${ }^{31}$ KUENZER, Acácia Zeneida. Ensino médio e profissional: as políticas do estado neoliberal. São Paulo : Cortez, 1997.

32 OLIVEIRA, Ramon de (2006). op. cit.; BUENO, Maria Sylvia Simões. Políticas atuais para o ensino médio. Campinas: Papirus, 2000; CUNHA, Luiz Antônio (2002). As agências financeiras internacionais e a reforma brasileira do ensino técnico: a crítica da crítica. In: ZIBAS, Dagmar M.L. et al. (Orgs.). O ensino médio e a reforma da educação básica. Brasília : Plano Editora, 2003.
33 BRASIL. Leis, Decretos. Decreto n. ${ }^{\circ} 2.208$, de 17 de abril de 1997. op. cit.

${ }^{34}$ Id. Decretos. Decreto n. ${ }^{\circ}$ 5.154, de 23 de julho de 2004. op. cit.

${ }^{35}$ FRIGOTTO, Gaudêncio et al. (Orgs.) (2005). op. cit.., p. 15.

${ }^{36}$ KUENZER, Acácia Zeneida (Org.) (2002). op. cit.; SAVIANI, Dermeval (1987) op. cit..

${ }^{37}$ SAVIANI, Dermeval (1987). op. cit.

${ }^{38}$ KUENZER, Acácia Zeneida (Org.) (2002). op. cit.

\section{ABSTRACT}

Ramon de Oliveira. Secondary school in question: analysis of a recent history.

The article analyzes the recent history of the Brazilian secondary school (1971-2006), using as reference the changes in the capitalist system and their implications for school pedagogic practice and the Brazilian public school financing. In that period, in addition to the substantial increase in enrolment in schools run by state governments, there was also a fertile debate on the secondary school social identity. Amidst the confrontation between academics and sectors linked to technological education, and the federal government, regarding the guarantee of not dissociating general and vocational education in secondary school, the lack of definition in relation to the secondary school social identity was maintained.

Keywords: Secondary School; History of Education; Education Policy; Education Financing; Brazil.

\section{RESUMEN}

Ramon de Oliveira. La enseñanza secundaria en cuestión: el análisis de una historia reciente.

Se analiza la historia reciente de la enseñanza secundaria brasileña (1971-2006) teniendo como referencia los cambios ocurridos en el sistema capitalistay sus implicaciones en la práctica pedagógica escolar y en la financiación de la educación pública brasileña. Se considera que durante este periodo, además del evidente aumento de la cantidad de inscripciones en las escuelas de la red estatal, el debate sobre la identidad social de la enseñanza secundaria fueprolifico. Es de destacar que en medio de la confrontación politica entre la universidad y los sectores vinculados a la enseñanza tecnológica y el gobierno federal, se mantiene la indefinición de la identidad social de dicha enseñanza en lo relacionado con la garantía de no disociación entre la formación general y profesional en la enseñana secundaria.

Palabras clave: Enseñanza Secundaria; Historia de la Educación; Política Educacional; Financiación de la Educación; Brasil. 